\title{
Designing Biodegradable and Active Multilayer System by Assembling an Electrospun Polycaprolactone Mat Containing Quercetin and Nanocellulose between Polylactic Acid Films
}

\author{
Carol López de Dicastillo ${ }^{1,2, *(\mathbb{C})}$, Luan Garrido ${ }^{1,2}$, Eliezer Velásquez ${ }^{1,2}$, Adrián Rojas ${ }^{1,2}$ (i) and Rafael Gavara ${ }^{3}$ (D) \\ 1 Packaging Innovation Center (LABEN-Chile), University of Santiago of Chile (USACH), \\ Obispo Umaña 050, Santiago 9170201, Chile; luan.garrido@usach.cl (L.G.); eliezer.velasquez@usach.cl (E.V.); \\ adrian.rojass@usach.cl (A.R.) \\ 2 Center for the Development of Nanoscience and Nanotechnology (CEDENNA), University of Santiago of \\ Chile (USACH), Obispo Umaña 050, Santiago 9170201, Chile \\ 3 Packaging Laboratory, Institute of Agrochemistry and Food Technology, IATA-CSIC, Av. Agustín Escardino 7, \\ 46980 Paterna, Spain; rgavara@iata.csic.es \\ * Correspondence: analopez.dediscastillo@usach.cl; Tel.: +56-951377492
}

\section{check for}

updates

Citation: López de Dicastillo, C.; Garrido, L.; Velásquez, E.; Rojas, A.; Gavara, R. Designing Biodegradable and Active Multilayer System by Assembling an Electrospun

Polycaprolactone Mat Containing Quercetin and Nanocellulose between Polylactic Acid Films. Polymers 2021, 13, 1288. https://doi.org/10.3390/ polym 13081288

Academic Editor: Sergio Torres-Giner

Received: 20 March 2021

Accepted: 13 April 2021

Published: 15 April 2021

Publisher's Note: MDPI stays neutral with regard to jurisdictional claims in published maps and institutional affiliations.

Copyright: (c) 2021 by the authors. Licensee MDPI, Basel, Switzerland. This article is an open access article distributed under the terms and conditions of the Creative Commons Attribution (CC BY) license (https:/ / creativecommons.org/licenses/by/ $4.0 /)$.
Abstract: The design of multilayer systems is an innovative strategy to improve physical properties of biodegradable polymers and introduce functionality to the materials through the incorporation of an active compound into some of these layers. In this work, a trilayer film based on a sandwich of electrospun polycaprolactone (PCL) fibers (PCLé) containing quercetin (Q) and cellulose nanocrystals (CNC) between extruded polylactic acid (PLA) films was designed with the purpose of improving thermal and barrier properties and affording antioxidant activity to packaged foods. PCLé was successfully electrospun onto $70 \mu \mathrm{m}$-thick extruded PLA film followed by the assembling of a third $25 \mu \mathrm{m}$-thick commercial PLA film through hot pressing. Optical, morphological, thermal, and barrier properties were evaluated in order to study the effect of PCL layer and the addition of Q and CNC. Bilayer systems obtained after the electrospinning process of PCL onto PLA film were also evaluated. The release of quercetin from bi- and trilayer films to food simulants was also analyzed. Results evidenced that thermal treatment during thermo-compression melted PCL polymer and resulted in trilayer systems with barrier properties similar to single PLA film. Quercetin release from bi- and trilayer films followed a similar profile, but achieved highest value through the addition of CNC.

Keywords: multilayer; biodegradable; polylactic acid; polycaprolactone; electrospinning

\section{Introduction}

Nowadays, concerns from a waste management point of view due to the substantial increase in the use of plastics has resulted in a strong research interest in the development of biodegradable materials as a good strategy to minimize the environmental impact of petroleum-based materials, principally used for food packaging applications [1,2]. There are several biodegradable polymers, such as polysaccharides, lipids, proteins, and others. Undoubtedly, PLA has become the most interesting material because it is commercially available, compostable, and produced at large industrial scale and can be processed by conventional melting extrusion processing [3,4]. However, PLA has certain disadvantages as its low thermal and barrier properties. The high permeability to gases and water vapor directly affects the packaged product by reducing the food shelf life. Therefore, the improvement of these properties through innovative technologies is a significant challenge for material scientists [5-7].

The development of multilayer materials has been considered a mechanism to improve material properties. Specifically, the improvement of barrier properties can occur by increasing the route of molecules diffusion through the layers of the materials. The mechanism is based on the synergistic effect between the properties of each of the materials 
that make up the complex structure [8]. Multilayer structures can be made by combining different polymers and using various techniques such as lamination, co-extrusion, coating, layer by layer, and more recently, the electrospinning technique [9-12]. Electrospinning is a simple, efficient, cost-effective and scalable technology capable of producing fibers. The fibrillary structures are obtained when a voltage is applied to a polymeric solution obtaining a jet with a conical structure known as "Taylor's Cone", from which the solvent evaporates to result in ultrafine structures with a high surface/volume ratio [13-16].

Nanotechnology has also shown up as an innovative technology to improve the mechanical and barrier properties of polymers over the last years. The attention has been focused on the incorporation of nanoreinforcements to polymeric matrices, such as nanoclays and nanocellulose $[17,18]$. Specifically, cellulose nanocrystals (CNC) have been one of the most researched nanofillers due to their excellent characteristics, such as highly crystalline structure, low density, biodegradability, transparency, and high specific area [5-7,9]. The polymeric matrix surrounds the reinforcing particles, resulting in composites with specific chemical or physical properties. This can occur through the formation of layers that can incorporate nanostructures to improve physical properties and also active agents to be released into food, both with the purpose of extending food shelf life. The development of active packaging by affording functionality to polymeric materials is a mechanism to generate added value and extend the shelf life of packaged food $[19,20]$. Because oxidation is one of the principal food deterioration processes, the design of materials incorporating antioxidants agents to be released into food is highly valuable [21,22].

Some biodegradable multilayer structures have been recently reported. Fabra et al. (2016) have developed a packaging material with very good oxygen and water vapor barrier properties, composed of electrospun polyhydroxybutyrate (PHB) fibers containing $\mathrm{CNC}$, and a nanocomposite based on corn starch and CNC, as substrate polymer [23]. Wan et al. (2016) have applied a thermal compression system to develop a multilayer film based on electrospun zein fibers onto a bacterial cellulose film as a support [24]. Bilayer systems based on electrospun fibers of PHB and PLA blends containing catechin onto poly(3-hydroxybutyrate-co-3-hydroxyvalerate) compressed molded film have also been developed and presented antioxidant activity in a fatty food simulant [25].

The novelty of this present work is the combination of electrospinning and hotpressing techniques using polycaprolactone electrospun fibers as a vehicle to incorporate the antioxidant compound and nanocellulose. A trilayer system based on electrospun fibers of polycaprolactone (PCL) containing quercetin $(\mathrm{Q})$, as a powerful antioxidant agent, and CNC between extruded PLA layers has been developed in order to improve the water vapor barrier and provide some protection to food against oxidative processes. The use of electrospinning for the development of active biodegradable packaging materials with a multilayer structure is complex, because, in most cases, there is no good adhesion between the electrospun layer and the substrate. In order to solve this problem, PCL fiber containing the active agent was assembled between two PLA layers. First, PCL fiber was electrospun on a PLA substrate, and then, a third PLA layer was incorporated onto PCL fibers through hot pressing process. This system was done to guarantee the fixation of the fibers into the active multilayer system and tune the active compound release. Quercetin, whose antioxidant, anti-inflammatory, anti-carcinogenic, and antiviral properties have been extensively demonstrated, is a phenolic compound found in fruits and vegetables. Its high antioxidant action through the free-radical scavenging activity has propitiated its use in the development of active packaging [26-30]. Meanwhile, PCL is a synthetic biodegradable semicrystalline polyester with low melting point (approximately $60^{\circ} \mathrm{C}$ ) and glass transition temperature (approximately $-60^{\circ} \mathrm{C}$ ); its mechanical and barrier properties make it an interesting polymer to be added in multilayer systems [31-33]. 


\section{Materials and Methods}

\subsection{Materials}

Polylactic acid (PLA), 2003D (specific gravity $\left.\frac{1}{4} 1.24 ; \mathrm{MFR} g / 10 \mathrm{~min}\left(210^{\circ} \mathrm{C}, 2.16 \mathrm{~kg}\right)\right)$, was purchased in pellet form from NatureWorks ${ }^{\circledR}$ Co., Minnetonka (Minnesota, MN, USA). Polycaprolactone (PCL) $\left(\overline{M_{n}}=80.000\right)$ and quercetin (Q) $(\geq 99.5 \%)$. Cellulose nanocrystals (CNC) were purchased from the University of Maine. Chloroform (CHF), ethanol, and $N, N$-dimethylformamide (DMF) were supplied by Merck (Santiago, Chile). Moreover, $25 \mu \mathrm{m}$ PLA films (PLA') were purchased by Q4 Packaging Systems, S.L. (Valencia, Spain).

\subsection{Preparation of Quercetin-Containing Multilayer Systems}

First, PLA films were flat melt-extruded in a twin-screw extruder Scientific Lab Tech LTE20 (Bangkok, Thailand) with a temperature profile of $200-210{ }^{\circ} \mathrm{C}$, a screw speed of $20 \mathrm{rpm}$, and $40 \%$ of torque. The resulting films presented an average thickness of around 65-70 $\mu \mathrm{m}$ measured by a digital micrometer Mitutoyo ID-C112.

Subsequently, bilayer films were prepared by coating one side of extruded PLA films with an electrospun PCL (PCLé) layer. Electrospinning was carried out using an electrospinning equipment (Spraybase ${ }^{\circledR}$ power Supply Unit, Maynooth, Ireland) with a horizontal configuration linked to a rotating collector connected to a high-voltage power and covered with mentioned PLA film. A PCL solution was first prepared by dissolving $14 \%(w / v)$ of this biopolymer in a DMF/CHF 3:7 $(v / v)$ mixture at room temperature. $\mathrm{Q}$ was subsequently added to the solution at $5 \%$ wt based on PCL weight. In the case of PCLé fibers containing CNC, CNC was finally added at $1 \%$ wt based on PCL weight. Solutions were gently stirred until homogenous solution was obtained. Parameters used were: distance needle-collector $12 \mathrm{~cm}$, voltage $6-7 \mathrm{kV}$, flow rate $0.4 \mathrm{~mL} \mathrm{~h}^{-1}$, collector speed $500 \mathrm{rpm}$, capillary speed $0.15 \mathrm{~m} \mathrm{~s}^{-1}$, and application time of $2.5 \mathrm{~h}$. The resulting bilayers PLA/PCL, PLA/PCL-Q, and PLA/PCL-Q-CNC films were named "B", "B-Q", and "B-Q$\mathrm{CNC}^{\prime}$, respectively. These bilayer systems were also analyzed in order to understand some physical properties.

The last stage focused in the incorporation of the third layer, the bilayer PCLécoated PLA films were hot-pressed with a neat PLA' film $(25 \mu \mathrm{m})$ at $90{ }^{\circ} \mathrm{C}$ without pressure for 1 min using a 4122-model press Carver, Inc. (Wabash, IN, USA). Final trilayer PLA/PCL/PLA', PLA/PCL-Q/PLA', and PLA/PCL-Q-CNC/PLA' films were named as "T", "T-Q", and "T-Q-CNC", respectively.

\subsection{Characterization of Physical Properties}

\subsubsection{Optical Parameter of Trilayer Systems}

The color properties of the films were measured in the CIELAB space in a Minolta colorimeter CR-410 Chroma Meter (Minolta Series, Tokyo, Japan). The colorimeter was calibrated with a white standard color plate, D65 illuminant and $2^{\circ}$ observer $\left(L^{*}=97.76\right.$, $\left.a^{*}=-0.04, b^{*}=1.90\right)$. Color parameters were the average from six measurements along each film. The color difference $\left(\Delta E^{*}\right)$ of each sample was calculated with respect to the PLA film by Equation (1):

$$
\Delta E=\sqrt{\left(\Delta a^{*}\right)^{2}+\left(\Delta b^{*}\right)^{2}+\left(\Delta L^{*}\right)^{2}},
$$

where $a^{*}, b^{*}$, and $L$ are the color coordinates, i.e., $L$ (lightness), $a^{*}$ (red-green), and $b^{*}$ (yellow-blue).

The opacity values of developed systems were also analyzed. Films were cut into $1 \mathrm{~cm} \times 4 \mathrm{~cm}$ pieces, and six replicates of each sample were measured. The absorbance values of each film were obtained with a UV-Vis mini 1240 spectrophotometer (Spectroquant ${ }^{\circledR}$ Pharo 300, Darmstadt, Germany) at a wavelength of $600 \mathrm{~nm}$. The opacity was determined from Equation (2) [34]:

$$
\text { Opacity }=\frac{A b s_{600 \mathrm{~nm}}}{X}
$$

where $A b_{600 \mathrm{~nm}}$ is the absorbance of films at $600 \mathrm{~nm}$ and $X$ is the thickness of every film. 


\subsubsection{Microstructural Analysis of Trilayer Systems}

The morphology of bi- and trilayer structures were analyzed using a scanning electron microscope (SEM) JSM-5410 JEOL5 with an accelerating voltage at $10 \mathrm{kV}$. The surface microstructure of the cryo-fractured cross-sections of bi- and trilayer systems were previously sputtered with a gold layer to make them conductive before observation.

\subsubsection{Thermal Properties of Bi- and Trilayer Systems}

Differential scanning calorimetry analysis was carried out in a Differential Scanning Calorimeter (Mettler-Toledo model STAR 822e, Greifensee, Switzerland) coupled to a cooling unit (HAAKE EK 90/mt, Newington, CO, USA). Samples were weighed into aluminum capsules using an analytical balance (Mettler Toledo GA135, Greifensee, Switzerland) with a precision of $0.1 \mathrm{mg}$. The weight of each sample was approximately $6-8 \mathrm{mg}$. The samples were subjected to a heating process from 0 to $250{ }^{\circ} \mathrm{C}$ at a constant speed of $10^{\circ} \mathrm{C} \mathrm{min}-1$ under nitrogen atmosphere.

The parameters reported were the glass transition temperature $\left(T_{g}\right)$, melting temperature $\left(T_{m}\right)$, cold crystallization temperature $\left(T_{c c}\right)$, enthalpies of melting $\left(\Delta H_{m}\right)$ and crystallization $\left(\Delta H_{c c}\right)$, and the percentage of the crystalline fraction of the PCL fiber and films according to each particular case. The crystallinity was calculated from Equation (3) [35] relating the value of the melting heat $\left(\Delta H_{m}\right)$ of each analyzed sample and the theoretical heat to melt the polymer with $100 \%$ crystallinity, in PLA $\left(\Delta H_{100}=93.6 \mathrm{~J} \mathrm{~g}^{-1}\right)$ and in the PCL $\left(\Delta H_{100}=139.3 \mathrm{~J} \mathrm{~g}^{-1}\right)[35,36]$.

$$
X_{c}=\frac{\Delta H_{m-} \Delta H_{c c}}{\Delta H_{100} \times X_{\text {Polimero }}} * 100(\%),
$$

where $X_{c}$ is crystalline fraction (\%), $\Delta H_{m}$ : enthalpy of melting of the sample $\left(\mathrm{J} \mathrm{g}^{-1}\right), \Delta H_{c c}$ is enthalpy of cold crystallization $\left(\mathrm{J} \mathrm{g}^{-1}\right)$, and $\Delta H_{100}$ is melting enthalpy of fully crystalline polymer $\left(\mathrm{J} \mathrm{g}^{-1}\right)$.

Thermogravimetric measurements were carried out in a Mettler Toledo Gas Controller GC20 Stare System TGA/DCS thermal analyzer (Schwerzenbach, Switzerland). The experiments were conducted under dynamic mode and under nitrogen atmosphere (flow rate of $50 \mathrm{~mL} \mathrm{~min}^{-1}$ ). Film samples were heated from room temperature to $600{ }^{\circ} \mathrm{C}$ at $10{ }^{\circ} \mathrm{C} \mathrm{min}{ }^{-1}$. Onset decomposition temperature ( $\left.T_{\text {onset }}\right)$ at $2.5 \mathrm{wt} \%$ of mass loss and temperature at the maximum degradation rate $\left(T_{d, \max }\right)$ were reported.

\subsubsection{Water Vapor Permeability (WVP) Analysis}

WVP values were gravimetrically analyzed at $50 \%$ and $90 \% \mathrm{RH}$ (relative humidity) and $23{ }^{\circ} \mathrm{C}$ using aluminum permeability cups in accordance with the standard method ISO 2528 [37]. The aluminum cups were filled with $7 \mathrm{~g}$ of silica gel and sealed with vacuum silicone grease and the films to be tested. The film was fixed in place with a flat Viton ring, an aluminum ring, and three press-screws. Then, relative humidity was ensured by storing the cups in desiccators containing salt solutions: magnesium nitrate $\left(\mathrm{Mg}\left(\mathrm{NO}_{3}\right)_{2}\right)$ and potassium sulfate $\left(\mathrm{K}_{2} \mathrm{SO}_{4}\right)$ for $50 \%$ and $90 \% \mathrm{RH}$, respectively. The cups were daily weighed for 2 weeks, and the plot of the weight increment versus time provided the water vapor transmission rate. These values were then divided by the water pressure gradient and film area and multiplied by the sample thickness to obtain the WVP value.

\subsection{Specific Migration Studies}

Release studies of quercetin from bi- and trilayer films were conducted by immersion of the films into two fatty food simulants according to EU Regulation $\mathrm{N}^{\circ} 10 / 2011$ about materials and plastic objects in contact with food at $40{ }^{\circ} \mathrm{C}[38,39]$. Double-sided, total immersion migration tests were carried out by total immersion of $3 \mathrm{~cm}^{2}$ pieces of each film in $5 \mathrm{~mL}$ of food simulant (area-to-volume ratio $=6 \mathrm{dm}^{2} / \mathrm{L}$ ) contained in a glass vial.

Released Q was analyzed by UV spectroscopy at $370 \mathrm{~nm}$ using a Pharo 300 Spectroquant ${ }^{\circledR}$ UV-VIS spectrophotometer (Darmstadt, Germany). The results were expressed as released 
quercetin concentration into the simulants using an absorbance/concentration $\left(\mathrm{g} \mathrm{mL}^{-1}\right)$ calibration curve.

\subsection{Statistical Analysis}

Data were analyzed through an analysis of variance (ANOVA) and Fisher's multiple range test using the Statgraphics Plus 5.1 program. The experimental design was random type where a $p$-value less than 0.05 indicated significant differences in the measurements between samples and was highlighted with different superscript letters.

\section{Results}

\subsection{Optical Properties}

Table 1 contains color parameters and opacity values of bi- and trilayer systems and PLA film. The visual appearance of these structures can be seen in Figure 1 that presents photographs of every polymeric system.

Table 1. Chromaticity coordinates, color variation, and opacity index of developed films.

\begin{tabular}{|c|c|c|c|c|c|c|}
\hline Films & Thickness ( $\mu \mathrm{m})$ & $L^{*}$ & $a^{*}$ & $b^{*}$ & $\Delta E^{*}$ & Opacity \\
\hline PLA & $79.4 \pm 6.9^{a}$ & $98.2 \pm 0.1^{\mathrm{d}}$ & $-0.05 \pm 0.01^{f}$ & $2.2 \pm 0.1^{\mathrm{a}}$ & - & $0.6 \pm 0.1^{a}$ \\
\hline B & $81.3 \pm 6.8^{a}$ & $97.5 \pm 0.1^{\mathrm{b}}$ & $-0.09 \pm 0.01^{\mathrm{e}}$ & $2.4 \pm 0.1^{\mathrm{c}}$ & $0.8 \pm 0.1^{b}$ & $12.8 \pm 1.3^{\mathrm{d}}$ \\
\hline B-Q & $83.6 \pm 8.9^{a}$ & $97.1 \pm 0.1^{\mathrm{a}}$ & $-0.51 \pm 0.03^{c}$ & $3.4 \pm 0.1^{\mathrm{e}}$ & $1.7 \pm 0.1^{\mathrm{d}}$ & $7.4 \pm 2.1^{c}$ \\
\hline $\mathrm{B}-\mathrm{Q}-\widehat{\mathrm{CNC}}$ & $83.5 \pm 8.1^{\mathrm{a}}$ & $97.2 \pm 0.1^{\mathrm{a}}$ & $-0.44 \pm 0.02^{\mathrm{d}}$ & $3.2 \pm 0.1^{\mathrm{d}}$ & $1.5 \pm 0.1^{\mathrm{c}}$ & $7.2 \pm 1.9^{c}$ \\
\hline $\mathrm{T}$ & $99.0 \pm 3.5^{\mathrm{a}}$ & $98.3 \pm 0.1^{\mathrm{d}}$ & $-0.11 \pm 0.01^{\mathrm{e}}$ & $2.3 \pm 0.1^{b}$ & $0.2 \pm 0.1^{\mathrm{a}}$ & $3.7 \pm 0.3^{b}$ \\
\hline $\mathrm{T}-\mathrm{Q}$ & $102.2 \pm 5.2^{b}$ & $97.9 \pm 0.1^{\mathrm{c}}$ & $-0.57 \pm 0.02^{b}$ & $3.9 \pm 0.1^{f}$ & $1.9 \pm 0.1^{\mathrm{e}}$ & $3.6 \pm 0.6^{b}$ \\
\hline $\mathrm{T}-\mathrm{Q}-\mathrm{CNC}$ & $103.7 \pm 4.3^{b}$ & $97.9 \pm 0.1^{\mathrm{c}}$ & $-0.61 \pm 0.02^{\mathrm{a}}$ & $3.9 \pm 0.1^{f}$ & $1.9 \pm 0.1^{\mathrm{e}}$ & $3.1 \pm 0.2^{b}$ \\
\hline
\end{tabular}

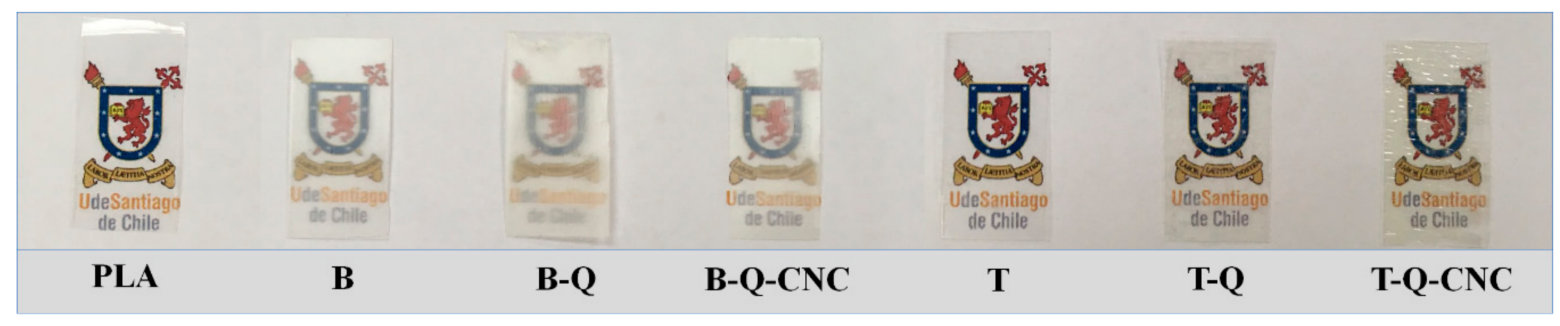

Figure 1. Photographs of developed polymeric systems.

The collection of electrospun PCL fibers on the PLA's surface caused a significant decrease in lightness $\left(L^{*}\right)$, a slight reduction in $a^{*}$ parameter, and an increase in $b^{*}$ parameter, obtaining a color difference $\Delta E^{*}=0.82$. Because the trilayer films were obtained through thermal-compression, PCLé melted and the parameters $L^{*}, a^{*}$, and $b^{*}$ were similar to the values of control PLA, increasing $L^{*}$ and decreasing the color difference $\Delta E^{*}$. The incorporation of $\mathrm{Q}$ in the PCLé fibers (samples B-Q and B-Q-CNC) increased $b^{*}$ value due to the yellow tone of this antioxidant agent and resulted in high values of $\Delta E^{*}$. Assuming that the limit value where the human eye perceives the change is $\Delta E^{*}=1$, a slight yellowish color was observed in these films $[40,41]$. As Figure 1 shows, this yellowish effect was higher when the fibers were hot pressed and covered by the third PLA' layer (samples T-Q and T$\mathrm{Q}-\mathrm{CNC}$ ). These trilayer systems presented higher values of luminosity $L^{*}$ and $b^{*}$ parameter. Yellowish color increased probably due to the release of $Q$ that was encapsulated into the electrospun PCL fibers when the system was hot pressed. The presence of CNC did not alter the color parameter of the materials probably due to its low concentration.

Regarding the bilayer structures, as shown in Figure 1, the electrospun PCL fibers onto the PLA significantly increased the opacity of the bilayer films. The high standard deviation values can be attributed to the fact that the light beam of the spectrophotometer passes through areas with variant presence of PCLé fibers since they were distributed as entangled 
threads on the PLA. Nonetheless, the trilayer films presented greater transparency because of the melting of the PCLé fibers associated with the hot pressing. The presence of CNC did not affect the transparency of the material.

In general terms, bilayer mats were more opaque than trilayer systems due to the presence of PCLé fibers with their original fibrillar morphologies. However, at the same time, the bilayer mats with $Q$ presented lower color difference than trilayer films because the thermal process caused the melting of PCLé-Q, and therefore, $Q$ was released, increasing the $b^{*}$ parameter.

\subsection{Morphological Analysis of Developed Trilayer Films}

Figure 2 shows the cross-sections of the developed active bi and trilayers systems at two magnifications. Images A-D of bilayer structures revealed the deposition of the electrospun fibers (PCLé) on the extruded PLA film. Average fiber diameters of PCLé-Q (Figure 2A,B) and PCLé-Q-CNC (Figure 2C,D) were analyzed with image analyzer software (Image J v1.37) and revealed diameters of $689.4 \pm 144.2$ and $614.8 \pm 110.7 \mathrm{~nm}$, respectively. PCLé-Q contained a final composition of 95.24 and $4.76 \%$ wt of PCL and Q, respectively, and PCLé-Q-CNC resulted on $94.34,4.72$, and $0.94 \%$ wt of PCL, Q and CNC, respectively. The incorporation of the antioxidant and the nanoreinforcements by electrospinning into PCL allowed an easy dispersion on the material on the PLA substrate and certain protection of these compounds. In addition, as Figure 2B,D shows, the deposition with the rotary collector led to an ordering and crossed orientation of the fibers.
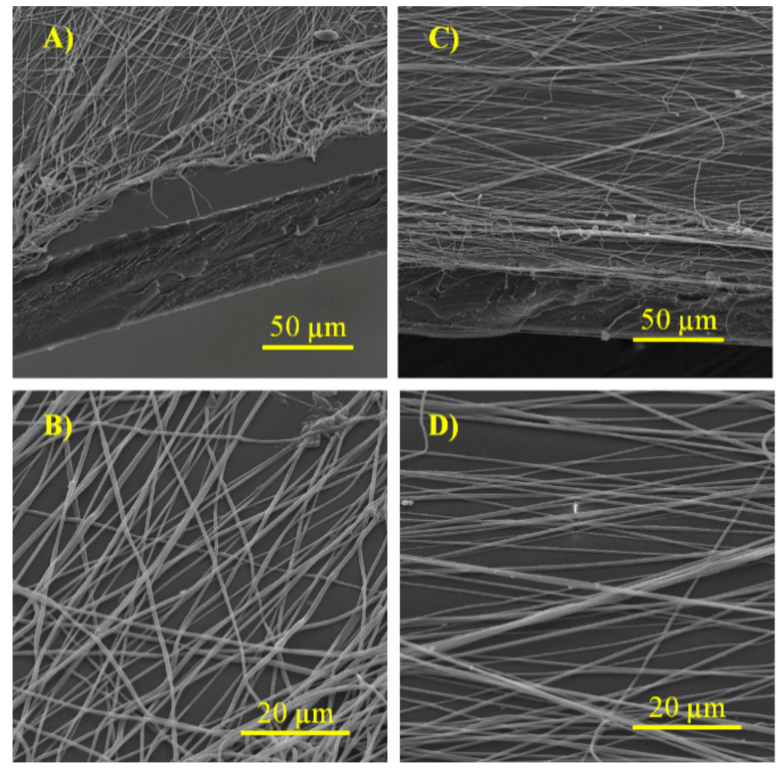
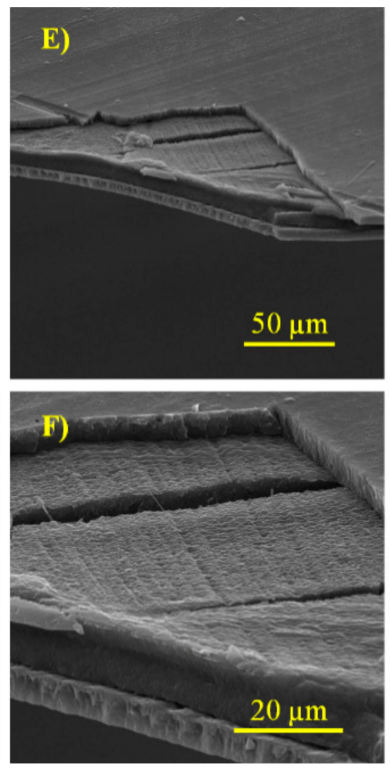
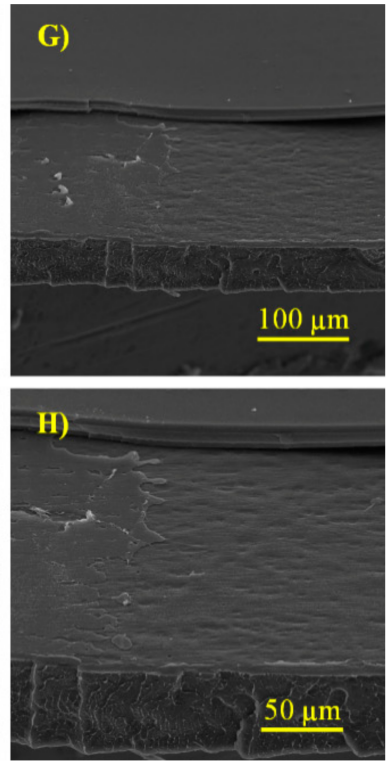

Figure 2. SEM micrographs of developed bi- and trilayer systems containing quercetin $(\mathrm{Q})$ and cellulose nanocrystals (CNC): (A,B) B-Q; (C,D) B-Q-CNC; (E,F) T-Q; and (G,H) T-Q-CNC.

Figure 2A reflects the low adhesion of PCLé-Q fibers on the PLA substrate, thus confirming the need for a third layer application and/or a heat treatment.

Figure 2E-H shows the images of the active trilayer films and the two main layers of PLA that got separated during the cryo-fracture process were clearly observed. The homogenous structure of these PLA layers was observed with greater definition because of their higher thickness. In addition, the loss of the fibrillary morphology of PCLé containing $\mathrm{Q}$ and $\mathrm{CNC}$ was also confirmed due to the heat treatment caused by the thermal-compression process. Although the thermal treatment applied during the thermocompression occurred for only one min at $90{ }^{\circ} \mathrm{C}$ without pressure, it was sufficient to melt PCL polymer due to its low melting temperature (approximately $60^{\circ} \mathrm{C}$, see Table 2). Therefore, PCLé layer displayed the effect as an adhesive role between the layers. 
Table 2. Differential scanning calorimetry (DSC) parameters of the mats during the first heating process.

\begin{tabular}{|c|c|c|c|c|c|c|c|}
\hline Films & $\begin{array}{c}T_{g} \\
\left({ }^{\circ} \mathrm{C}\right)\end{array}$ & $\begin{array}{l}T_{c c} \\
\left({ }^{\circ} \mathrm{C}\right)\end{array}$ & $\begin{array}{c}\Delta H_{c c} \\
\left(\mathrm{Jg}^{-1}\right)\end{array}$ & $\begin{array}{l}T_{m 1} \\
\left({ }^{\circ} \mathrm{C}\right)\end{array}$ & $\begin{array}{l}T_{m 2} \\
\left({ }^{\circ} \mathrm{C}\right)\end{array}$ & $\begin{array}{c}\Delta H_{m} \\
\left(\mathrm{~J} \mathrm{~g}^{-1}\right)\end{array}$ & $\begin{array}{c}X_{c} \\
(\%)\end{array}$ \\
\hline PCLé & - & - & - & $59.2 \pm 0.8^{a}$ & - & $108.7 \pm 1.1^{b}$ & $78.0 \pm 0.8^{\mathrm{e}}$ \\
\hline PLA film & $63.5 \pm 0.1^{b}$ & $114.7 \pm 0.1^{b c}$ & $37.3 \pm 0.5^{b}$ & $149.2 \pm 0.1^{\mathrm{c}}$ & $153.9 \pm 0.3^{b}$ & $39.2 \pm 0.1^{\mathrm{a}}$ & $2.0 \pm 0.6^{\mathrm{ab}}$ \\
\hline B & $63.2 \pm 0.5^{b}$ & $115.1 \pm 0.4^{c}$ & $36.6 \pm 0.3^{b}$ & $149.1 \pm 0.4^{c}$ & $153.6 \pm 0.2^{b}$ & $38.4 \pm 0.3^{a}$ & $1.9 \pm 0.1 \mathrm{ab}$ \\
\hline B-Q & $63.1 \pm 0.3^{b}$ & $115.2 \pm 0.2^{c}$ & $33.2 \pm 4.1^{b}$ & $149.3 \pm 0.1^{\mathrm{c}}$ & $153.8 \pm 0.1^{b}$ & $36.5 \pm 3.9^{a}$ & $3.6 \pm 0.2^{b}$ \\
\hline B-Q-CNC & $63.1 \pm 0.2^{b}$ & $114.9 \pm 0.1^{b c}$ & $36.5 \pm 1.5^{b}$ & $148.9 \pm 0.2^{c}$ & $153.6 \pm 0.2^{b}$ & $37.4 \pm 1.7^{\mathrm{a}}$ & $1.0 \pm 0.2^{\mathrm{a}}$ \\
\hline $\mathrm{T}$ & $61.1 \pm 0.1^{a}$ & $114.5 \pm 0.2^{\mathrm{ab}}$ & $20.1 \pm 2.1^{a}$ & $147.4 \pm 0.3^{b}$ & $152.3 \pm 0.2^{\mathrm{a}}$ & $38.1 \pm 0.6^{a}$ & $19.1 \pm 1.6^{d}$ \\
\hline T-Q & $61.1 \pm 0.1^{\mathrm{a}}$ & $113.9 \pm 0.1^{\mathrm{a}}$ & $23.2 \pm 0.2^{\mathrm{a}}$ & $147.1 \pm 0.2^{b}$ & $152.0 \pm 0.3^{\mathrm{a}}$ & $38.8 \pm 0.1^{\mathrm{a}}$ & $16.7 \pm 0.1^{\mathrm{c}}$ \\
\hline T-Q-CNC & $60.5 \pm 0.7^{\mathrm{a}}$ & $114.0 \pm 0.5^{\mathrm{a}}$ & $23.7 \pm 2.1^{\mathrm{a}}$ & $147.6 \pm 0.9^{b}$ & $151.6 \pm 0.7^{\mathrm{a}}$ & $37.4 \pm 0.4^{\mathrm{a}}$ & $14.7 \pm 1.8^{\mathrm{c}}$ \\
\hline
\end{tabular}

Values were reported as the mean and standard deviation of two measurements. Superscripts a-e indicate significant differences through ANOVA analysis $(p<0.05)$.

\subsection{Thermal Properties}

Table 2 shows the main thermal properties of developed films. DSC parameters and crystallinities of bilayer systems (B) and PLA monolayer presented similar values, displaying a $T_{g}$ around $63^{\circ} \mathrm{C}$ and a melting transition with two shoulders, evidencing crystals with different morphologies or lamellar thicknesses [29]. The effect of the incorporation of $\mathrm{Q}$ and CNC into PCLé on the thermal properties of the bilayer films was not significant. On the contrary, thermal parameters and crystallinity degrees of trilayer films exhibited significant differences compared to bilayer systems. During the thermal-compression, the heat transference to the films caused a polymer rearrangement evidenced by low $\Delta H_{c c}$ values and highest $X_{c}$ degrees. Thermal parameters of trilayer systems were similar regardless of the presence of $Q$ and $C N C$. Nonetheless, the crystallinity diminished when $Q$ and $C N C$ were incorporated in the inner layer, possibly because of steric hindrance and interactions between the components that hindered the chain mobility and reordering during the compression and the cooling process. These interactions could be hydrogen-bond type between hydroxyl, carbonyl groups, and oxygen (ether group) of $\mathrm{Q}$ and hydroxyl and ether groups of CNC, or intermolecular interactions between their hydroxyl and carbonyl groups of the polyesters. PCL-Q and PLA-CNC interactions in electrospun active mats have been previously reported $[35,42]$. Meanwhile, hydrogen-bond type interactions between $C N C-Q$, PLA-Q, and PCL-CNC have been reported in polymeric films $[29,43,44]$.

Furthermore, $T_{g}$ values of trilayer films were slightly reduced, attributed to the plasticizing effect of the PCL chains in the inner layer, which owns high flexibility with $T_{g}$ value of approximately $-40^{\circ} \mathrm{C}$ [45]. Although both bi- and trilayer films contain PCL, this polymer in the trilayer films suffered a melting process that implied their different behavior as an adhesive between PLA layers, and its plasticizing effect was possibly enhanced. Likewise, the high mobility of PCL chains in the trilayer films caused the cold crystallization and the collapse of the crystals for melting started at slightly lower temperatures than bilayer films and PLA control. The absence of the PCL melting transition in bi- and trilayer mats can be attributed to its low fraction into the films, approximately $2.4 \%$ and $1.7 \%$ with respect to total weight in the bi- and trilayer films, respectively. Meanwhile, the absence of thermal transitions of $C N C$ and $Q$ is due to their low concentration in the films. Similar results have been observed in zein/PLA bilayer films containing $Q$ and CNC [29].

Conversely, TGA thermograms of all PLA films displayed a single main degradation process regarding the decomposition of PLA chains into carboxylic acids, aldehydes, and lactide monomers and/or oligomers [46]. PCLé also showed a single degradation stage in which a random cleavage of PCL chains produces water, carbon dioxide, and 5-hexenoic, and an unzipping depolymerization produces $\mathcal{E}$-caprolactone [42]. As Table 3 shows, TGA parameters of PLA film were not affected by the electrospun PCL layer without $\mathrm{Q}$ and CNC. However, $T_{\text {onset }}$ was significantly reduced in the trilayer films, possibly due to the fact that flexible PCL chains promoted an earlier network degradation in 
concordance to DSC analysis. However, the incorporation of $\mathrm{Q}$ and CNC reduced the $T_{\text {onset }}$ of bi- and trilayer films due to their decomposition at $T_{d . m a x}$ lower than PLA. $T_{d}$ of $\mathrm{Q}$ has been reported around $350{ }^{\circ} \mathrm{C}$ attributed to the degradation of the aromatic rings, lower than $T_{d, \max }$ of PLA $\left(364.3^{\circ} \mathrm{C}\right)[29,47,48]$. Q has also presented a mass loss of $10 \mathrm{wt} \%$ approximately up to $160^{\circ} \mathrm{C}$ attributed to the elimination of water molecules [47,48]. Despite of lipophilicity of $Q$, hydroxyl groups of this polyphenolic compound in the solid-state form intermolecular hydrogen bond with water molecules [49]. Q was not degraded by the temperature of hot pressing process because its maximum degradation occurs at $355^{\circ} \mathrm{C}$ approx. [29]. Meanwhile, CNC decomposition has been previously reported from $289.6^{\circ} \mathrm{C}$, with maximum degradation rates associated with hydroxyl $-\mathrm{CH}_{2}-\mathrm{OH}$ groups removal at $294{ }^{\circ} \mathrm{C}$, and cellulose chain degradation at $354{ }^{\circ} \mathrm{C}$ [29]. In addition, the lower crystallinity degree of trilayer films with $\mathrm{Q}$ and $\mathrm{Q} / \mathrm{CNC}$ promoted their decomposition starting at lower temperatures and produced higher mass loss percentages (see Table 3 ).

Table 3. TGA parameters of the films.

\begin{tabular}{cccc}
\hline Films & $\boldsymbol{T}_{\text {onset }}\left({ }^{\circ} \mathbf{C}\right)$ & $\boldsymbol{T}_{d, \max }\left({ }^{\circ} \mathbf{C}\right)$ & Mass Loss at $\boldsymbol{T}_{d, \max }(\mathbf{w t} \%)$ \\
\hline PLA film & 335.1 & 364.3 & 56.4 \\
\hline PCLé fiber & 351.4 & 412.7 & 56.5 \\
\hline B & 335.7 & 364.3 & 56.3 \\
B-Q & 330.9 & 363.2 & 56.5 \\
B-Q-CNC & 330.4 & 366.1 & 59.2 \\
\hline T & 309.5 & 363.6 & 59.3 \\
T-Q & 304.8 & 363.7 & 61.1 \\
T-Q-CNC & 305.5 & 364.3 & 61.2 \\
\hline
\end{tabular}

\subsection{Water Vapor Barrier Properties}

In addition to being a vehicle for the incorporation of quercetin for the development of an antioxidant material, the PCLé layer was intended to improve the water barrier property of the resulting material due to the nature of PCL polymer and the incorporation of CNC. Water vapor permeability $\left(\mathrm{P}_{\mathrm{H} 2 \mathrm{O}}\right)$ results of the trilayer systems at two relative humidities are shown in Figure 3. At RH 50\%, a slight improvement was observed in the films containing $\mathrm{CNC}$, but the differences with other systems were not statistically significant with respect to a control PLA* film, possibly due to the low concentration of this nanoreinforcement with respect to the total volume of the material. $\mathrm{P}_{\mathrm{H} 2 \mathrm{O}}$ of PLA* film, an $80 \mu \mathrm{m}$ extruded PLA film, was included in order to have a reference [29].

All samples evidenced a considerable increase in permeability values when moving to high relative humidity due to the hydrophilic nature of the polymers. As it was already observed in previous studies, the sorption of water vapor molecules presented a plasticizing effect and the mobility of the polymer chains increased, and, therefore, the diffusivity considerably increased. The incorporation of the thin PCL layer did not have the desired effect, possibly due to its low thickness, which could have been also reduced as a consequence of the thermal-compression process. Interestingly, the incorporation of quercetin dramatically increased at RH 90\%. Possibly, the higher interaction between this antioxidant compound and water enhanced its plasticizing effect. The incorporation of CNC counteracted this effect, and T-Q-CNC film exhibited lower permeability values than T-Q at both humidities. 


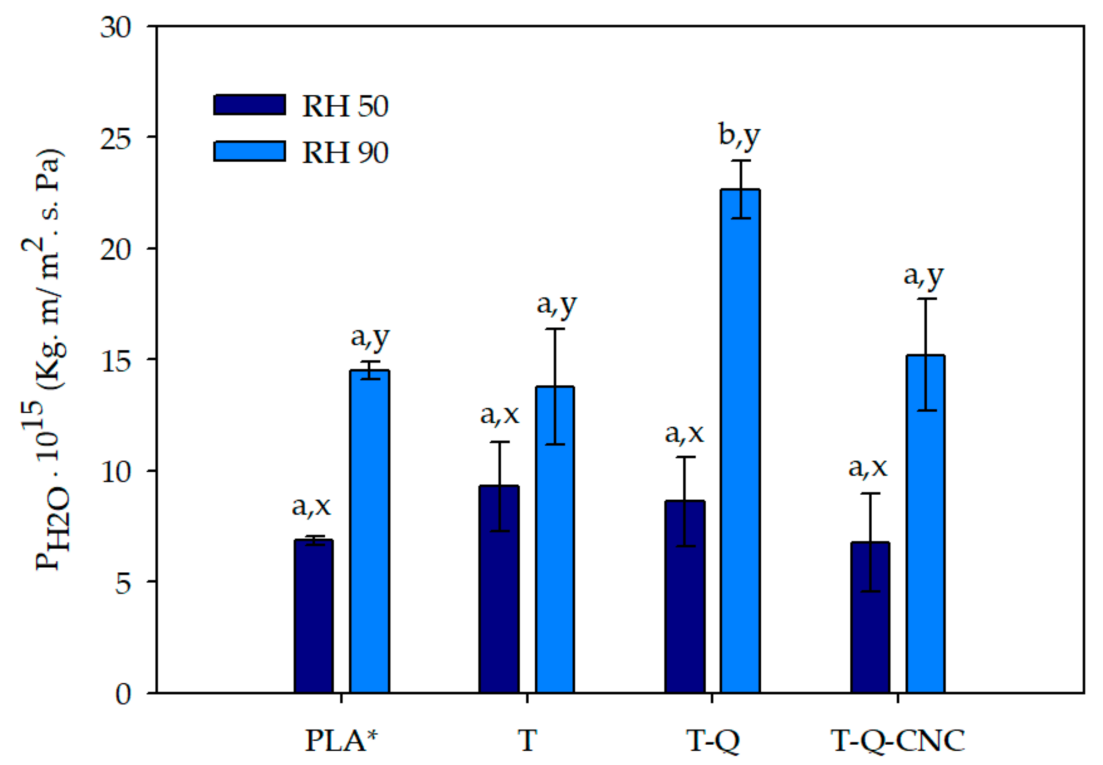

Figure 3. Water vapor permeability values of developed trilayer systems and PLA* (extruded PLA $80 \mu \mathrm{m})$. Case letters $\mathrm{a}, \mathrm{b}$ indicate significant differences among the values of permeability of different films at the same relative humidity $(\mathrm{RH})$; letters $x, y$ indicate significant differences among the values of permeability of the same sample at different values of $\mathrm{RH}$ ).

\subsection{Quercetin Release Studies}

Figure 4 presents the results of released quercetin from bi- (B-Q and B-Q-CNC) and trilayer (T-Q and T-Q-CNC) systems in both fatty food simulants at the equilibrium condition for specific migration assays. It is important to mention that, although the thermocompression process under the described conditions gave rise to a good layer adhesion between films, corresponding layers could have been partially detached when immersed into food simulants during migration tests. A high degree of polymeric swelling was exhibited, promoting and evidencing similar degree of $Q$ release rate between all films. Therefore, significant differences on the diffusion of $Q$ through the films were not observed.
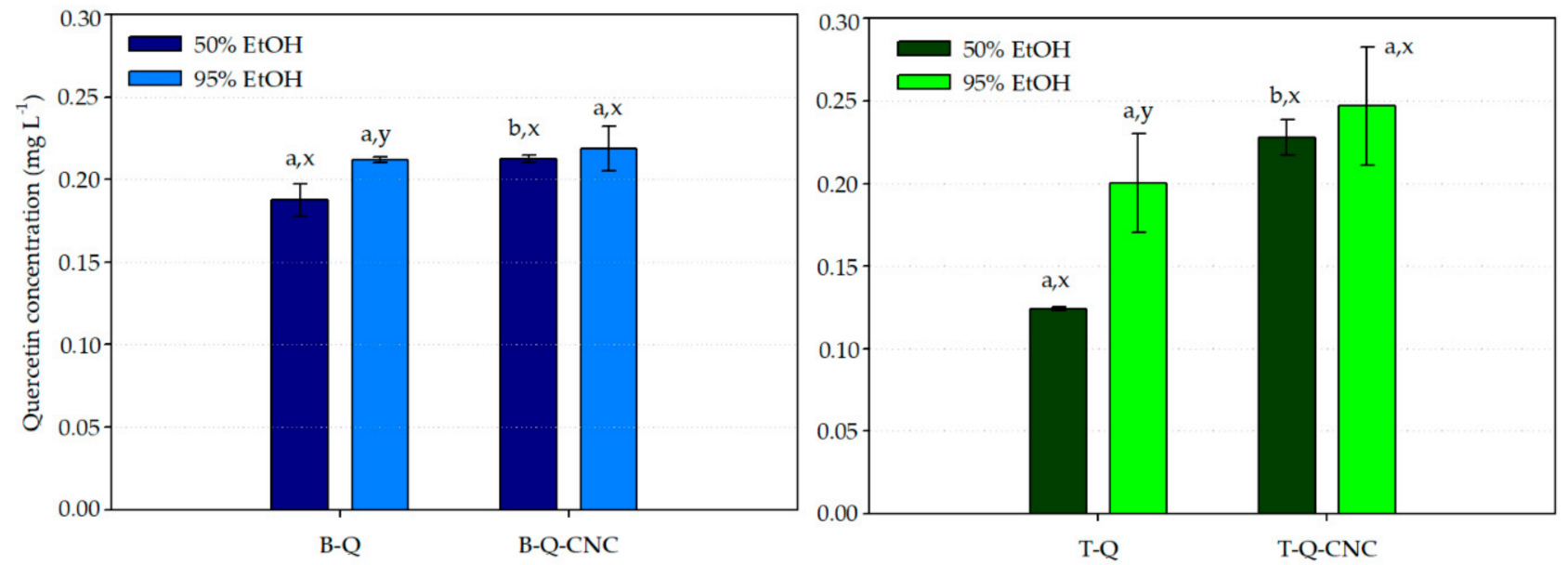

Figure 4. Released $\mathrm{Q}$ at the equilibrium condition from B-Q and B-Q-CNC bilayer films (left) and T-Q and T-Q-CNC trilayer films (right) into $\mathrm{EtOH} \mathrm{50 \%} \mathrm{and} \mathrm{EtOH} \mathrm{95 \% .} \mathrm{Case} \mathrm{letters} \mathrm{a,b} \mathrm{indicate} \mathrm{significant} \mathrm{differences} \mathrm{among} \mathrm{the} \mathrm{values} \mathrm{of} Q$ released from films of bi- and trilayer systems in the same food simulant, and letters $x, y$ indicate significant differences among the values of $Q$ released from the same film into different food simulants.

In the case of films without the addition of $\mathrm{CNC}$, the highest values of quercetin concentration at the equilibrium condition in both food simulants were obtained from 
the bilayer films. This fact could be explained because quercetin in the bilayer films was included into PCLé whose fibrillar and porous structure facilitated the food simulant absorption into their structure, and consequently, the $Q$ release. Conversely, the values of released $Q$ from trilayer $T-Q$ films at the equilibrium condition slightly decreased probably because of the presence of the third PLA' layer, which could chemically interact with $Q$ and hinder its release. This phenomenon was dependent on the food simulant, obtaining a slightly higher value of Q concentration into $\mathrm{EtOH} 95 \%$ for both B-Q and T-Q films. This fact could be explained in terms of the higher chemical affinity and solubility of this antioxidant into ethanol $[30,50]$. The lower tendency of quercetin to migrate from the trilayer film could be consequence of several factors associated to the thermodynamic equilibrium for the mass transfer of migrants from polymers. In this case, the main factors could be: (1) lower absorption of food simulant in the PCLé layer due to its third highly crystalline PLA' layer; (2) a decrease in the quercetin gradient concentration because of the increase in the polymer mass due to the addition of the PLA' layer; and (3) the availability of some functional groups in PLA for its interaction with quercetin, which increased the affinity of quercetin towards the trilayer film.

Figure 4 also evidenced that the addition of $\mathrm{CNC}$ in the bi- and trilayer structures significantly modified the migration tendency of $Q$ released, principally in $95 \%$ food simulant, probably because the presence of CNC affected the main structural properties of PCLé, which governed the thermodynamical equilibrium for mass transfer as crystallinity degree (see Section 3.3). Q was released in more extent from the T-Q-CNC trilayer film in both food simulants compared to the values obtained for the T-Q trilayer film. This behavior was dependent on the food simulant. The higher tendency of $Q$ to migrate from the nanoreinforced trilayer films could be related to the fact that the hot-pressing process caused a polymer rearrangement, which could promote specific interactions between the polymers and CNC to the detriment of its interaction with Q. Moreover, the T-Q-CNC trilayer film presented a lower crystallinity degree than the T-Q film, which could promote the sorption of food simulant and the polymer swelling degree and, therefore, the $Q$ release.

\section{Conclusions}

The combination of different polymeric processing techniques allows the development of biodegradable multilayer systems. Electrospinning was an innovative and simple technique that enabled the homogenous incorporation of quercetin and cellulose nanocrystals, as an active compound and nanoreinforcement, into a thin layer of the biodegradable trilayer film in order to provide antioxidant activity and the improvement of physical properties. The incorporation of a non-volatile antioxidant agent allows the extension of the shelf life and/or effectiveness of this packaging material to long periods, being surely more dependent of the shelf life of both polymers. In this context, this is a weakness on biodegradable packaging that should be addressed.

Results revealed that hot pressing can be an adequate processing technique to assemble polymeric layers, although the stability and adherence between them will be dependent on chemical structure of polymers. Although thermal analysis indicated an increase on crystallinity, trilayer system did not exhibit improvements on water barrier properties. The systems exhibited antioxidant activity in fatty food simulants, and the incorporation of cellulose nanocrystals entailed a higher quercetin release. Developed trilayer systems showed their potential as active materials, but further investigation is needed to be applied as food packaging.

Author Contributions: Conceptualization, C.L.d.D.; methodology, L.G., C.L.d.D. and R.G.; formal analysis, C.L.d.D., L.G., E.V. and A.R.; investigation, C.L.d.D. and L.G.; resources, C.L.d.D.; data curation, C.L.d.D., L.G., E.V. and A.R.; writing-original draft preparation, C.L.d.D., E.V. and A.R.; writing-review and editing, C.L.d.D., E.V. and A.R.; supervision, C.L.d.D.; project administration, C.L.d.D.; funding acquisition, C.L.d.D. All authors have read and agreed to the published version of the manuscript. 
Funding: This research was funded by FONDECYT REGULAR 1200766 and "Programa de Financiamiento Basal para Centros Científicos y Tecnológicos de Excelencia" Project FB0807.

Institutional Review Board Statement: Not applicable.

Informed Consent Statement: Not applicable.

Data Availability Statement: Not applicable.

Conflicts of Interest: The authors declare no conflict of interest.

\section{References}

1. Mangaraj, S.; Yadav, A.; Bal, L.M.; Dash, S.K.; Mahanti, N.K. Application of Biodegradable Polymers in Food Packaging Industry: A Comprehensive Review. J. Packag. Technol. Res. 2019, 3, 77-96. [CrossRef]

2. Rydz, J.; Musioł, M.; Zawidlak-Węgrzyńska, B.; Sikorska, W. Present and Future of Biodegradable Polymers for Food Packaging Applications. Biopolym. Food Des. 2018, 431-467. [CrossRef]

3. Ahmed, J.; Varshney, S.K. Polylactides-Chemistry, Properties and Green Packaging Technology: A Review. Int. J. Food Prop. 2011, 14, 37-58. [CrossRef]

4. Nofar, M.; Sacligil, D.; Carreau, P.J.; Kamal, M.R.; Heuzey, M.C. Poly (lactic acid) blends: Processing, properties and applications. Int. J. Biol. Macromol. 2019, 125, 307-360. [CrossRef] [PubMed]

5. Qian, S.; Sheng, K.; Yu, K.; Xu, L.; Fontanillo Lopez, C.A. Improved properties of PLA biocomposites toughened with bamboo cellulose nanowhiskers through silane modification. J. Mater. Sci. 2018, 53, 10920-10932. [CrossRef]

6. López de Dicastillo, C.; Garrido, L.; Alvarado, N.; Romero, J.; Palma, J.; Galotto, M. Improvement of Polylactide Properties through Cellulose Nanocrystals Embedded in Poly(Vinyl Alcohol) Electrospun Nanofibers. Nanomaterials 2017, 7, 106. [CrossRef] [PubMed]

7. López de Dicastillo, C.; Roa, K.; Garrido, L.; Pereira, A.; Galotto, M. Novel Polyvinyl Alcohol/Starch Electrospun Fibers as a Strategy to Disperse Cellulose Nanocrystals into Poly(lactic acid). Polymers 2017, 9, 117. [CrossRef] [PubMed]

8. Cerqueira, M.A.; Torres-Giner, S.; Lagaron, J.M. Chapter 6-Nanostructured Multilayer Films. In Micro and Nano Technologies; Cerqueira, M.Â.P.R., Lagaron, J.M., Pastrana Castro, L.M., de Oliveira Soares Vicente, A.A.M., Eds.; Elsevier: Amsterdam, The Netherlands, 2018; pp. 147-171. ISBN 978-0-323-51271-8.

9. Messin, T.; Marais, S.; Follain, N.; Guinault, A.; Gaucher, V.; Delpouve, N.; Sollogoub, C. Biodegradable PLA/PBS multinanolayer membrane with enhanced barrier performances. J. Memb. Sci. 2020, 598, 117777. [CrossRef]

10. Gu, C.H.; Wang, J.J.; Yu, Y.; Sun, H.; Shuai, N.; Wei, B. Biodegradable multilayer barrier films based on alginate/polyethyleneimine and biaxially oriented poly(lactic acid). Carbohydr. Polym. 2013, 92, 1579-1585. [CrossRef] [PubMed]

11. Liu, D.; Dong, Y.; Bhattacharyya, D.; Sui, G. Novel sandwiched structures in starch/cellulose nanowhiskers (CNWs) composite films. Compos. Commun. 2017, 4, 5-9. [CrossRef]

12. Mao, J.; Tang, Y.; Zhao, R.; Zhou, Y.; Wang, Z. Preparation of nanofibrillated cellulose and application in reinforced PLA/starch nanocomposite film. J. Polym. Environ. 2019, 27, 728-738. [CrossRef]

13. Soares, R.M.D.; Siqueira, N.M.; Prabhakaram, M.P.; Ramakrishna, S. Electrospinning and electrospray of bio-based and natural polymers for biomaterials development. Mater. Sci. Eng. C 2018, 92, 969-982. [CrossRef]

14. Maftoonazad, N.; Ramaswamy, H. Novel techniques in food processing: Bionanocomposites. Curr. Opin. Food Sci. 2018, 23, 49-56. [CrossRef]

15. Huang, Z.M.; Zhang, Y.Z.; Kotaki, M.; Ramakrishna, S. A review on polymer nanofibers by electrospinning and their applications in nanocomposites. Compos. Sci. Technol. 2003, 63, 2223-2253. [CrossRef]

16. Agarwal, S.; Greiner, A.; Wendorff, J.H. Functional materials by electrospinning of polymers. Prog. Polym. Sci. 2013, 38, 963-991. [CrossRef]

17. Bordes, P.; Pollet, E.; Avérous, L. Nano-biocomposites: Biodegradable polyester/nanoclay systems. Prog. Polym. Sci. 2009, 34, 125-155. [CrossRef]

18. Bari, S.S.; Chatterjee, A.; Mishra, S. Biodegradable polymer nanocomposites: An overview. Polym. Rev. 2016, 56, 287-328. [CrossRef]

19. Tavassoli, M.; Sani, M.A.; Khezerlou, A.; Ehsani, A.; McClements, D.J. Multifunctional nanocomposite active packaging materials: Immobilization of quercetin, lactoferrin, and chitosan nanofiber particles in gelatin films. Food Hydrocoll. 2021, 106747. [CrossRef]

20. Soltani Firouz, M.; Mohi-Alden, K.; Omid, M. A critical review on intelligent and active packaging in the food industry: Research and development. Food Res. Int. 2021, 141, 110113. [CrossRef]

21. Jacob, J.; Thomas, S.; Loganathan, S.; Valapa, R.B. Antioxidant incorporated biopolymer composites for active packaging. In Processing and Development of Polysaccharide-Based Biopolymers for Packaging Applications; Elsevier: Amsterdam, The Netherlands, 2020; pp. 239-260.

22. Pateiro, M.; Domínguez, R.; Bermúdez, R.; Munekata, P.E.S.; Zhang, W.; Gagaoua, M.; Lorenzo, J.M. Antioxidant active packaging systems to extend the shelf life of sliced cooked ham. Curr. Res. Food Sci. 2019, 1, 24-30. [CrossRef] 
23. Fabra, M.J.; López-Rubio, A.; Ambrosio-Martín, J.; Lagaron, J.M. Improving the barrier properties of thermoplastic corn starchbased films containing bacterial cellulose nanowhiskers by means of PHA electrospun coatings of interest in food packaging. Food Hydrocoll. 2016, 61, 261-268. [CrossRef]

24. Wan, Z.; Wang, L.; Yang, X.; Guo, J.; Yin, S. Enhanced water resistance properties of bacterial cellulose multilayer films by incorporating interlayers of electrospun zein fibers. Food Hydrocoll. 2016, 61, 269-276. [CrossRef]

25. Arrieta, M.P.; García, A.D.; López, D.; Fiori, S.; Peponi, L. Antioxidant bilayers based on PHBV and plasticized electrospun PLA-PHB fibers encapsulating catechin. Nanomaterials 2019, 9, 346. [CrossRef] [PubMed]

26. Li, S.; Yan, Y.; Guan, X.; Huang, K. Preparation of a hordein-quercetin-chitosan antioxidant electrospun nanofibre film for food packaging and improvement of the film hydrophobic properties by heat treatment. Food Packag. Shelf Life 2020, $23,100466$. [CrossRef]

27. Bai, R.; Zhang, X.; Yong, H.; Wang, X.; Liu, Y.; Liu, J. Development and characterization of antioxidant active packaging and intelligent Al 3+-sensing films based on carboxymethyl chitosan and quercetin. Int. J. Biol. Macromol. 2019, 126, 1074-1084. [CrossRef]

28. Braga, L.R.; Pérez, L.M.; Soazo, M.d.V.; Machado, F. Evaluation of the antimicrobial, antioxidant and physicochemical properties of Poly(Vinyl chloride) films containing quercetin and silver nanoparticles. LWT 2019, 101, 491-498. [CrossRef]

29. Velásquez, E.; Rojas, A.; Piña, C.; Galotto, M.J.; López de Dicastillo, C. Development of bilayer biodegradable composites containing cellulose nanocrystals with antioxidant properties. Polymers 2019, 11, 1945. [CrossRef]

30. López de Dicastillo, C.; Alonso, J.; Catalá, R.; Gavara, R.; Hernández-Munoz, P. Improving the antioxidant protection of packaged food by incorporating natural flavonoids into ethylene-vinyl alcohol copolymer (EVOH) films. J. Agric. Food Chem. 2010, 58. [CrossRef]

31. Sogut, E.; Seydim, A.C. Development of Chitosan and Polycaprolactone based active bilayer films enhanced with nanocellulose and grape seed extract. Carbohydr. Polym. 2018, 195, 180-188. [CrossRef]

32. Mugwagwa, L.R.; Chimphango, A.F.A. Enhancing the functional properties of acetylated hemicellulose films for active food packaging using acetylated nanocellulose reinforcement and polycaprolactone coating. Food Packag. Shelf Life 2020, $24,100481$. [CrossRef]

33. Nair, N.R.; Sekhar, V.C.; Nampoothiri, K.M.; Pandey, A. Biodegradation of Biopolymers. In Current Developments in Biotechnology and Bioengineering: Production, Isolation and Purification of Industrial Products; Elsevier: Amsterdam, The Netherlands, 2016; pp. 739-755; ISBN 9780444636621.

34. Velásquez, E.; Garrido, L.; Valenzuela, X.; Galotto, M.J.; Guarda, A.; López de Dicastillo, C. Physical properties and safety of 100\% post-consumer PET bottle -organoclay nanocomposites towards a circular economy. Sustain. Chem. Pharm. 2020, 17, 100285. [CrossRef]

35. Rojas, A.; Velásquez, E.; Garrido, L.; Galotto, M.J.; López de Dicastillo, C. Design of active electrospun mats with single and core-shell structures to achieve different curcumin release kinetics. J. Food Eng. 2020, 273. [CrossRef]

36. Jenkins, M.J.; Harrison, K.L. The effect of molecular weight on the crystallization kinetics of polycaprolactone. Polym. Adv. Technol. 2006, 17, 474-478. [CrossRef]

37. ISO-ISO 2528:1995—Sheet Materials—Determination of Water Vapour Transmission Rate—Gravimetric (Dish) Method. Available online: https:/ / www.iso.org/standard/20676.html (accessed on 18 March 2021).

38. Feigenbaum, A.E.; Riquet, A.M.; Scholler, D. Fatty food simulants: Solvents to mimic the behavior of fats in contact with packaging plastics. ACS Symp. Ser. 2000, 753, 71-81. [CrossRef]

39. Lajarrige, A.; Gontard, N.; Gaucel, S.; Peyron, S. Evaluation of the Food Contact Suitability of Aged Bio-Nanocomposite Materials Dedicated to Food Packaging Applications. Appl. Sci. 2020, 10, 877. [CrossRef]

40. Bodart, M.; de Peñaranda, R.; Deneyer, A.; Flamant, G. Photometry and colorimetry characterisation of materials in daylighting evaluation tools. Build. Environ. 2008, 43, 2046-2058. [CrossRef]

41. Higueras, L.; López-Carballo, G.; Hernández-Muñoz, P.; Gavara, R.; Rollini, M. Development of a novel antimicrobial film based on chitosan with LAE (ethyl-N $\alpha$-dodecanoyl-1-arginate) and its application to fresh chicken. Int. J. Food Microbiol. 2013, 165, 339-345. [CrossRef]

42. Rojas, A.; Velásquez, E.; Piña, C.; Galotto, M.J.; López de Dicastillo, C. Designing active mats based on cellulose acetate/polycaprolactone core/shell structures with different release kinetics. Carbohydr. Polym. 2021, 261, 117849. [CrossRef]

43. Latos-Brozio, M.; Massek, A. Impregnation of Poly(lactic Acid) with Polyphenols of Plant Origin. Fibres Text. East. Eur. 2020, 28, 15-20. [CrossRef]

44. Bi, H.; Ren, Z.; Ye, G.; Sun, H.; Guo, R.; Jia, X.; Xu, M. Fabrication of cellulose nanocrystal reinforced thermoplastic polyurethane/polycaprolactone blends for three-dimension printing self-healing nanocomposites. Cellulose 2020, 27, 8011-8026. [CrossRef]

45. Bassi, A.K.; Gough, J.E.; Zakikhani, M.; Downes, S. The Chemical and Physical Properties of Poly( $(\varepsilon$-caprolactone) Scaffolds Functionalised with Poly(vinyl phosphonic acid-co-acrylic acid). J. Tissue Eng. 2011, 2011. [CrossRef]

46. Herrera-Kao, W.A.; Loría-Bastarrachea, M.I.; Pérez-Padilla, Y.; Cauich-Rodríguez, J.V.; Vázquez-Torres, H.; Cervantes-Uc, J.M. Thermal degradation of poly(caprolactone), poly(lactic acid), and poly(hydroxybutyrate) studied by TGA/FTIR and other analytical techniques. Polym. Bull. 2018, 75, 4191-4205. [CrossRef] 
47. Milia, A.; Bruno, M.; Cavallaro, G.; Lazzara, G.; Milioto, S. Adsorption isotherms and thermal behavior of hybrids based on quercetin and inorganic fillers. J. Therm. Anal. Calorim. 2019, 1-7. [CrossRef]

48. Muthurajan, T.; Rammanohar, P.; Rajendran, N.P.; Sethuraman, S.; Krishnan, U.M. Evaluation of a quercetin-gadolinium complex as an efficient positive contrast enhancer for magnetic resonance imaging. RSC Adv. 2015, 5, 86967-86979. [CrossRef]

49. Vaz, G.R.; Clementino, A.; Bidone, J.; Villetti, M.A.; Falkembach, M.; Batista, M.; Barros, P.; Sonvico, F.; Dora, C. Curcumin and Quercetin-Loaded Nanoemulsions: Physicochemical Compatibility Study and Validation of a Simultaneous Quantification Method. Nanomaterials 2020, 10, 1650. [CrossRef]

50. López de Dicastillo, C.; Gómez-Estaca, J.; Catalá, R.; Gavara, R.; Hernández-Muñoz, P. Active antioxidant packaging films: Development and effect on lipid stability of brined sardines. Food Chem. 2012, 131. [CrossRef] 